\title{
Role of Frailty in Natural History of Degenerative Aortic Stenosis in Older Patients
}

\author{
Ramos $\mathbf{M}^{1}$, Quezada DM ${ }^{1}$, Ayala $\mathbf{R}^{1}$, Pavón FJG ${ }^{1}$, Hidalgo $\mathrm{JJ}^{1}$ and Toro $\mathbf{R}^{2}$ \\ ${ }^{1}$ Central Hospital of the Red Cross San José and Santa Adela, Cardiology, Madrid, Spain \\ ${ }^{2}$ Institute of Research and Innovation in Biomedical Sciences of the Province of Cadiz (INiBICA), University of Cadiz, Cadiz, Spain
}

"Corresponding author: Ramos M, Central Hospital of the Red Cross San José and Santa Adela, Cardiology, Madrid, Spain, Tel: + 34914538300; E-mail: monica.ramos81@gmail.com

Received: February 14, 2018; Accepted: February 25, 2019; Published: February 28, 2019

Copyright: @ 2019 Ramos M, et al. This is an open-access article distributed under the terms of the creative commons attribution license, which permits unrestricted use, distribution, and reproduction in any medium, provided the original author and source are credited.

\section{Commentary}

Degenerative aortic stenosis (AS) is a very prevalent pathology in the elderly, representing a growing proportion of the population in developed countries [1]. Currently, cardiology outpatient clinics are often attended by this type of patient who, in addition to serious valvular pathology and their advanced age, has a greater number of comorbidities and geriatric syndromes.

Knowledge of the natural evolution of degenerative AS in the elderly and detection of the different factors that influence its prognosis is essential. On the one hand, to detect on time those who are going to benefit from invasive treatments and decide the most appropriate type of management and, on the other hand, to prevent rapid deterioration of the patient that leads to an irreversible situation of dependence, hospitalizations and frailty.

The results presented in our study provide novel aspects regarding the natural history of AS in elderly patients [2]. The assessment of geriatric patients with AS should include more than the anatomical and functional data of the aortic valve and the left ventricle since frailty and dependence can mask the symptoms of the disease, thus delaying surgical treatment and increasing the risk of hospitalization due to congestive heart failure (CHF). As we have seen among our patients, timely and early detection of symptoms is often difficult in elderly patients due to the presence of other comorbidities or because they are self-limiting, being sometimes the first manifestation of symptoms a CHF admission. This fact may imply that the patient is in a very advanced state of both valvulopathy and frailty with less possibility of invasive options.

CHF is the most important cause of hospitalization in our population and is the reason for up to $40.8 \%$ of admissions for patients with AS [3]. Studies have analyzed the economic impact of conservative treatment for older patients with severe AS and report an important health expense [4]. Therefore, determining which factors could increase the risk of hospitalization in this population is crucial for clinical decision making.

In this study, we defined for the first time some predictors of CHF admission in patients with moderate-severe degenerative AS, such as age, atrial fibrillation, renal failure, a high logistic EuroSCORE value, frailty and aortic valvular area. Forty-five percent of our population experienced at least one $\mathrm{CHF}$ admission episode, with an average of $2.6 \pm 1.5$ admissions. Of the 104 asymptomatic patients included in our study one half experienced their first CHF admission three years after the degenerative AS diagnosis; however, among patients older than 85 years, this period shortened to eight months.
The assessment of frailty is becoming an indispensable tool in decision making. It is a geriatric syndrome characterized by an increase in vulnerability to even minor stress which results from the decline in multiple physiological systems and it may be a cause of functional disability and it may be reversible or attenuated with adequate intervention $[5,6]$.

Although the role of frailty is clear in patients prior to intervention [7], until now it has not been assessed its role in the history of the AS and what happens with the frail patients who have not yet been operated. In our study, frailty was a powerful marker of $\mathrm{CHF}$ admissions. Among our cohort, $59.6 \%$ met the frailty criteria, and 69.4\% of these frail patients experienced a CHF hospitalization during the follow-up period. This association occurs because frailty itself can affect the myocardial tissue, which leads to greater myocardial injury and a worse response to overload, favoring the occurrence of CHF. In addition, chronic $\mathrm{CHF}$ as a result of valvulopathy produces alterations in skeletal muscle and body composition, and the patients subsequently develop frailty [8].

In our study, the mean time to the first admission for CHF in frail patients was 1.08 years, indicating an increased risk of hospitalization. Currently, the assessment of frailty is essential for patients undergoing surgery, especially those who are candidates for transcatheter aortic valve implantation (TAVI) $[9,10]$. Almost $40-50 \%$ of patients who have undergone TAVI show poor health outcomes, either due to death or because their clinical status does not improve $[11,12]$. There is a wide variety of tools available to measure frailty and there is no consensus on which tools to use. In case of using Fried's criteria, we would find a high prevalence of frailty, and that is why it has been proposed to apply harder parameters, such as the inability to walk, the dependence on basic activities of daily life or hypoalbuminemia that allow a better risk discrimination [13]. Recently the investigators of the FRAILTY-AVR study prospectively evaluated the incremental value of 7 different scales to standard risk algorithm in predicting poor outcomes following TAVI and surgical aortic valve replacement (SARV) [14]. The results demonstrated that the essential frailty toolset (EFT) had the highest predictive value for death at 1 year and was the strongest predictor of worsening disability at one year as well as death at 30 days. However, frailty should not be a reason for exclusion in all cases because the AS may be the cause of frailty and because there are aspects of frailty that may be reversible. In this sense, the setting for rehabilitative procedures could prevent some episodes of CHF and improve the prognosis of an invasive procedure. All the information must be integrated in the decision-making process, ensuring the benefit derived from each treatment in each patient, optimizing the resources and avoiding futility. 
Traditional risk scores, including STS PROM and logistic EuroSCORE have proven insufficient to predict events in elderly patients with severe AS [15]. However, we have associated CHF hospitalization with the logistic EuroSCORE. The variables included in this score, such as age, high serum creatinine levels and chronic obstructive pulmonary disease, are prevalent in our population and have been shown to be predictors of events in patients with AS [16].

Another factor associated with CHF hospitalization was the presence of atrial fibrillation that was observed in $43 \%$ of the study population and increased to $61 \%$ among patients who were admitted to the hospital. New-onset atrial fibrillation has been considered an early mortality marker and a more severe stage of the disease that forces the consideration of invasive management $[17,18]$. However, pre-existing atrial fibrillation may have an adverse impact on postTAVI morbidity and mortality.

Finally, regarding comorbidities, also very prevalent in our population, renal failure was associated with an earlier CHF hospitalization. It is a well-known factor associated with the rapid progression of AS [19] and it has also been related to the mortality of these patients [20] as well as operative mortality, especially in elderly patients [21].

In conclusion, both cardiological, and geriatric assessments are essential for making decisions regarding surgical timing for these patients. Multidisciplinary teams are necessary to evaluate and select patients who could benefit from invasive versus conservative treatment. This could mean a decrease in the number of hospitalizations due to CHF, an improvement in the quality of life of patients and a reduction in health costs.

\section{References}

1. Iung B, Baron G, Butchart EG, Delahaye F, Gohlke-Bärwolf C, et al. (2003) A prospective survey of patients with valvular heart disease in Europe: The euro heart survey on valvular heart disease. Eur Heart J 24: 1231-1243.

2. Ramos M, Quezada DM, Ayala R, Gómez-Pavón FJ, Jaramillo J, et al. (2019) Aortic stenosis prognosis in older patients: Frailty is a strong marker of early congestive heart failure admissions. Eur Geriatr Med: 1-9.

3. Retegui G, Ogalla S, Pérez R, Cobo M, Marín J, Ruiz M (2010) Evolution of elderly patients admitted for severe aortic stenosis and rejected for surgical intervention. Rev Esp Geriatr Gerontol 45: 335-338.

4. Clark MA, Arnold SV, Duhay FG, Thompson AK, Keyes MJ, et al. (2012) Five-year clinical and economic outcomes among patients with medically managed severe aortic stenosis: Results from a Medicare claims analysis. Circ Cardiovasc Qual Outcomes 5: 697-704.

5. Rockwood K, Hogan DB, MacKnight C (2000) Conceptualisation and measurement of frailty in elderly people. Drugs Aging 17: 295-302.
6. Clegg A, Young J, Iliffe S, Rikkert MO, Rockwood K (2013) Frailty in elderly people. Lancet 381: 752-762.

7. Baumgartner H, Falk V, Bax JJ, De Bonis M, Hamm C, et al. (2017) 2017 ESC/EACTS guidelines for the management of valvular heart disease. Eur Heart J 38: 2739-2791.

8. Persinger R, Janssen-Heininger Y, Wing SS, Matthews DE, Le Winter MM, et al. (2003) Effect of heart failure on the regulation of skeletal muscle protein synthesis, breakdown and apoptosis. Am J Physiol Endocrinol Metab 284: E1001-E1008.

9. Otto CM, Kumbhani DJ, Alexander KP, Calhoon JH, Desai MY, et al. (2017) 2017 ACC expert consensus decision pathway for transcatheter aortic valve replacement in the management of adults with aortic stenosis: A report of the American College of Cardiology Task Force on Clinical Expert Consensus Documents. J Am Coll Cardiol 69: 1313-1346.

10. Díez-Villanueva P, Salamanca J, Rojas A, Alfonso F (2017) Importance of frailty and comorbidity in elderly patients with severe aortic stenosis. J Geriatr Cardiol 14: 379-382.

11. Leon MB, Smith CR, Mack M, Miller DC, Moses JW, et al. (2010) Transcatheter aortic-valve implantation for aortic stenosis in patients who cannot undergo surgery. N Engl J Med 363: 1597-1607.

12. Mack MJ, Stoler R (2017) Intervention for aortic stenosis: The measurement of frailty matters. J Am Coll Cardiol 70: 701-703.

13. Afilalo J, Alexander KP, Mack MJ, Maurer MS, Green P, et al. (2014) Frailty assessment in the cardiovascular care of older adults. JACC 63: 747-762.

14. Afilalo J, Lauck S, Kim DH, Lefèvre T, Piazza N, et al. (2017) Frailty in older adults undergoing aortic valve replacement: The frailty-avr study. J Am Coll Cardiol 70: 689-700.

15. Zbroński K, Huczek Z, Puchta D, Paczwa K, Kochman J, et al. (2016) Outcome prediction following transcatheter aortic valve implantation: Multiple risk scores comparison. Cardiol J 23: 169-177.

16. Monin JL, Lancellotti P, Monchi M, Lim P, Weiss E, et al. (2009) Risk score for predicting outcome in patients with asymptomatic aortic stenosis. Circulation 120: 69-75.

17. Greve AM, Gerdts E, Boman K, Gohlke-Baerwolf C, Rossebø AB, et al. (2013) Prognostic importance of atrial fibrillation in asymptomatic aortic stenosis: The Simvastatin and Ezetimibe in Aortic Stenosis study. Int J Cardiol 166: 72-76.

18. Levy F, Rusinaru D, Maréchaux S, Charles V, Peltier M, et al. (2015) Determinants and prognosis of atrial fibrillation in patients with aortic stenosis. Am J Cardiol. 116: 1541-1546.

19. Kamath AR, Pai RG (2008) Risk factors for progression of calcific aortic stenosis and potential therapeutic targets Int J Angiol 17: 63-70.

20. Pellikka PA, Sarano ME, Nishimura RA, Malouf JF, Bailey KR, et al. (2005) Outcome of 622 adults with asymptomatic, hemodynamically significant aortic stenosis during prolonged follow-up. Circulation 111: 3290-3295.

21. Iung B, Cachier A, Baron G, Messika-Zeitoun D, Delahaye F, et al. (2005) Decision-making in elderly patients with severe aortic stenosis: Why are so many denied surgery?. Eur Heart J 26: 2714-2720. 